\title{
Construction of Stratospheric Temperature Data Records from Stratospheric Sounding Units
}

\author{
LIKUN WANG \\ Dell Services Federal Government, Fairfax, Virginia \\ CHENG-ZHI ZOU \\ NOAA/NESDIS/STAR, Camp Springs, Maryland \\ HAIFENG QIAN \\ I.M. Systems Group, Inc., Rockville, Maryland
}

(Manuscript received 20 June 2011, in final form 11 October 2011)

\begin{abstract}
In recognizing the importance of Stratospheric Sounding Unit (SSU) onboard historical NOAA polarorbiting satellites in assessment of long-term stratospheric temperature changes and limitations in previous available SSU datasets, this study constructs a fully documented, publicly accessible, and well-merged SSU time series for climate change investigations. Focusing on methodologies, this study describes the details of data processing and bias corrections in the SSU observations for generating consistent stratospheric temperature data records, including 1) removal of the instrument gas leak effect in its $\mathrm{CO}_{2}$ cell; 2) correction of the atmospheric $\mathrm{CO}_{2}$ increase effect; 3) adjustment for different observation viewing angles; 4) removal of diurnal sampling biases due to satellite orbital drift; and 5) statistical merging of SSU observations from different satellites. After reprocessing, the stratospheric temperature records are composed of nadirlike, gridded brightness temperatures that correspond to identical weighting functions and a fixed local observation time. The 27-yr reprocessed SSU data record comprises global monthly and pentad layer temperatures, with grid resolution of $2.5^{\circ}$ latitude by $2.5^{\circ}$ longitude, of the midstratosphere (TMS), upper stratosphere (TUS), and top stratosphere (TTS), which correspond to the three SSU channel observations. For 1979-2006, the global mean trends for TMS, TUS, and TTS, are respectively $-1.236 \pm 0.131,-0.926 \pm 0.139$, and $-1.006 \pm$ $0.194 \mathrm{~K} \mathrm{decade}^{-1}$. Spatial trend pattern analyses indicated that this cooling occurred globally with larger cooling over the tropical stratosphere.
\end{abstract}

\section{Introduction}

The Stratospheric Sounding Unit (SSU) on board the National Oceanic and Atmospheric Administration polar-orbiting satellite series is a three-channel infrared (IR) radiometer designed to measure temperatures in the stratosphere. The weighting functions of these channels are centered at near $15,5.0$, and $1.5 \mathrm{hPa}$, as shown in Fig. 1, respectively, corresponding to layer temperatures from mid to top stratosphere (Miller et al. 1980). Though mainly designed to provide the stratospheric temperature

Corresponding author address: Dr. Cheng-Zhi Zou, Center for Satellite Applications and Research, NOAA/NESDIS, NOAA Science Center, Room 712, 5200 Auth Road, Camp Springs, MD 20746. E-mail: cheng-zhi.zou@noaa.gov information for weather forecasting models (Kobayashi et al. 2009), the SSU was the only instrument making near-global stratospheric temperature observations over a long-term period from 1979 to 2006 until the Advanced Microwave Sounding Unit (AMSU) observations were available. Therefore, the SSU long-term observations have been extensively used for assessment of temperature changes in the stratosphere and their possible causes (e.g., Nash and Brownscombe 1983; Nash and Forrester 1986; Nash 1988; Brindley et al. 1999; Ramaswamy et al. 2001; Shine et al. 2003; Gray et al. 2009; Randel et al. 2009; Liu and Weng 2009; World Meteorological Organization 1988, 2007; Young et al. 2011, 2012).

However, several limitations inherent in the SSU measurements made construction of homogeneous, consistent long-term SSU data records a challenging task. First, since 


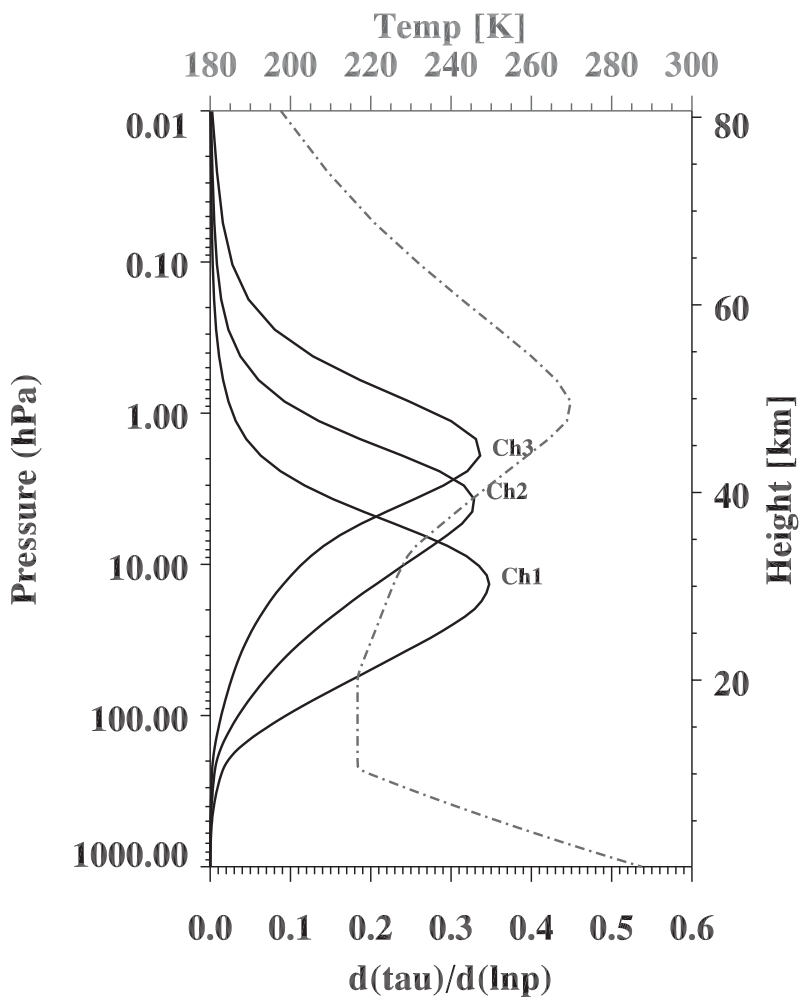

FIG. 1. Weighting functions of three SSU channels, overlaid with the temperature profile from the U.S. Standard Atmosphere, 1976. It was calculated based on the standard atmosphere with a zero scan angle, 330 ppmv atmospheric $\mathrm{CO}_{2}$, and cell pressures of 110 , $40,15 \mathrm{hPa}$ for SSU three channels.

the SSU was a pressure modulator radiometer (PMR), an on-board $\mathrm{CO}_{2}$ cell was used in spectral filtering. During the satellite operational period, unfortunately, $\mathrm{CO}_{2}$ gas leakage occurred for all satellites. This caused the instrument cell pressure to decrease and channel weighting functions to peak at different layers with satellite operational time, resulting in a time-varying change in brightness temperature (BT) measurements (Brindley et al. 1999; Kobayashi et al. 2009; Chen et al. 2011). In addition, the cell pressures were not identical among different SSU instruments, which introduced intersatellite biases when linking the observations on different satellites.

Second, the SSU instruments sense radiation in the 15- $\mu \mathrm{m}$ atmospheric $\mathrm{CO}_{2}$ absorption band and, hence, their weighting functions are sensitive to changes in atmospheric $\mathrm{CO}_{2}$ concentration (Shine et al. 2008; Chen et al. 2011). As atmospheric $\mathrm{CO}_{2}$ slowly increased, the weighting functions of the three SSU channels would gradually move to higher altitude. Consequently, spurious positive temperature trends would be superimposed on the SSU temperature trend, which must be corrected when using the SSU observations to study stratospheric temperature change.

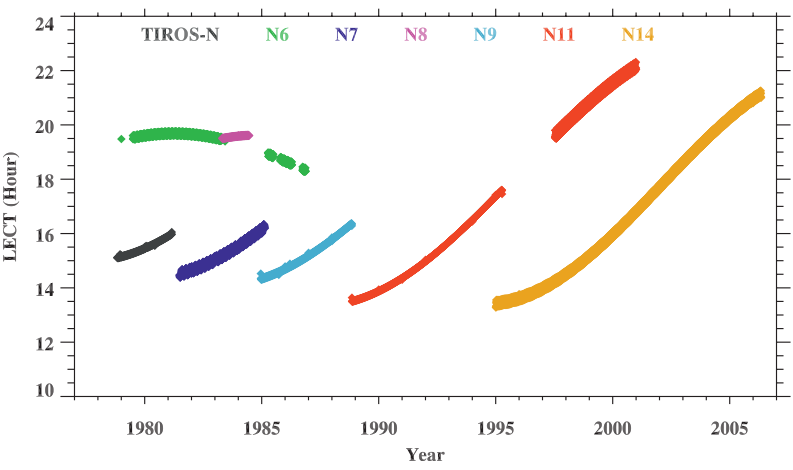

FIG. 2. Local equator crossing time (LECT) of the ascending orbits of the operational NOAA satellites that carried SSU instruments.

Third, satellite orbital drift may cause diurnal sampling biases in satellite observations (Brownscombe et al. 1985; Nash and Forrester 1986). The SSU observations came from seven different satellites. The first SSU was launched in 1978 on the Next-Generation Television and Infrared Operational Satellite (TIROS-N). After that, NOAA had launched six other satellites carrying SSU instruments, including NOAA-6, -7, $-8,-9,-11$, and -14. These satellites circled Earth in sun-synchronous orbits at heights between 830 and $870 \mathrm{~km}$. Of them, NOAA-6 and NOAA-8 had local equator crossing times (LECT) occurring at 0730 (descending) and 1930 (ascending) local time (LT) and thus were called "morning satellites," while TIROS-N, NOAA-7, -9, -11, and -14 crossed the equator at 0230 (descending) and 1430 (ascending) LT and hence were referred to as "afternoon satellites". During the life cycle of a given satellite, the actual LECT gradually changed because of orbital drift. Figure 2 illustrates the equatorial ascending crossing times for the seven NOAA polar-orbiting satellites carrying the SSU instruments. As the satellites drifted through different observation times in the diurnal cycle, the observed BTs increased or decreased depending on the observational time of the day. In the stratosphere, the temperature fields have diurnal and semidiurnal tidal variations because the stratosphere is periodically heated as ozone absorbs solar radiation during the day (Lindzen and Chapman 1969). Therefore, corrections have to be made to account for this diurnal sampling bias.

Finally, the generation of a 27-yr SSU dataset needs to link the SSU measurements together from separate satellites. Unfortunately, the SSU instruments were not flown on $N O A A-10$ and -12 , and no data were available from NOAA-13 because of a spacecraft circuit failure. Additionally, there were almost no overlap observations between NOAA-9 and NOAA-11 (Fig. 2). These missing data issues cause errors in intersatellite calibration 
and merging and, thus, lead to uncertainties in climate trend determinations.

Owing to the above challenges, only very limited SSU analyses are available. The pioneer work by Nash and his colleagues (Nash and Brownscombe 1983; Nash and Forrester 1986; Nash 1988) developed the first SSU analysis, which has been widely used for assessing stratospheric temperature trends. The Nash SSU dataset includes three nadir channels from two near-nadir (a viewing angle of $5^{\circ}$ ) pixels (denoted as channels 25, 26, and 27), together with four synthetic channels derived from combinations and differences of near-nadir (a viewing angle of $5^{\circ}$ ) and off-nadir (a viewing angle of $35^{\circ}$ ) observations (so-called $\mathrm{x}$ channels, 15x, 26x, 36x, and $47 x$ ). The data are available as monthly zonal-mean temperature anomalies on a $10^{\circ}$ latitude grid covering $70^{\circ} \mathrm{N}$ to $70^{\circ} \mathrm{S}$ from January 1979 to December 2005. Nash SSU analysis was recently updated by considering the effects of increases in atmospheric $\mathrm{CO}_{2}$ concentration on the trends of stratosphere temperature (Shine et al. 2008; Randel et al. 2009). Lately, Liu and Weng (2009) have produced an alternative analysis for SSU channels 25 and 26. In their recent review paper, Seidel et al. (2011) compared the global time series of SSU channels 25 and 26 from these two datasets and identified large discrepancies between them. However, for both SSU analyses (Nash and Forrester 1986; Liu and Weng 2009), the details of data processing were not clearly described in peer-reviewed literatures, and thus the root causes of the difference between them are difficult to explore.

Acknowledgment of the above limitations has led to our efforts to construct an alternative fully documented, publicly accessible, well-merged long-term SSU dataset to be used for climate change studies. Our aim is to create a new SSU dataset with nadirlike, gridded BTs that correspond to identical weighting functions with a fixed local observational time from three SSU channels by exploiting the observations from all view angles. We take advantage of the recent advances in the SSU radiative transfer modeling development in our data construction (Kobayashi et al. 2009; Chen et al. 2011) to handle the varying instrument cell pressures and increasing atmospheric $\mathrm{CO}_{2}$ concentration. Three SSU channels are referred as channels 1, 2, and 3 in this study, which correspond to channels 25, 26, and 27 in Nash dataset. The channel products are also named as layer temperatures of the midstratosphere (TMS), upper stratosphere (TUS), and top stratosphere (TTS) based on their weighting function characteristics (see Fig. 1).

This paper documents the details of data construction procedures and its effects on SSU measurements. It is organized as follows: section 2 introduces the data

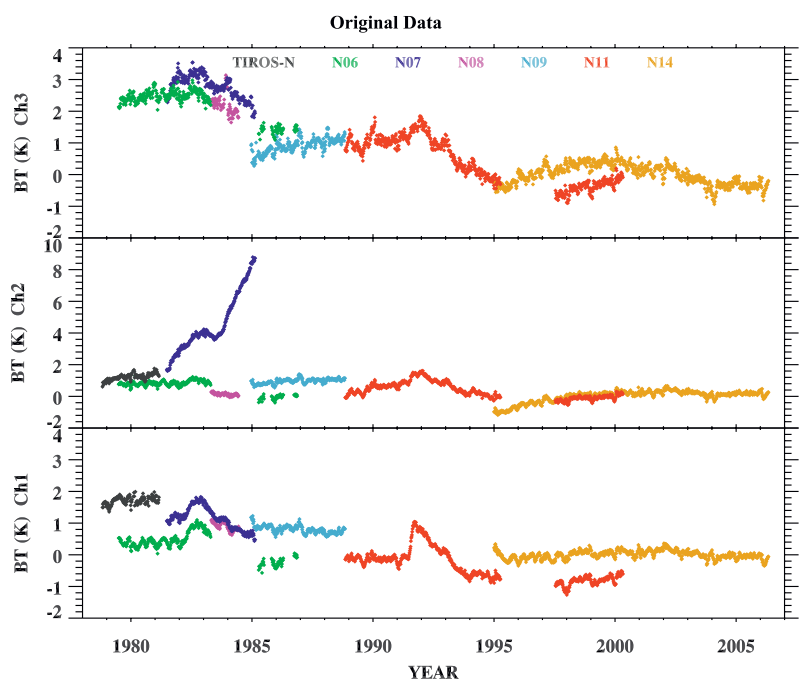

FIG. 3. Global mean pentad SSU BT anomalies from the original SSU measurements with respect to the 1995-2005 mean.

processing method, section 3 presents the results, and section 4 provides the conclusions.

\section{Methods}

The SSU data used in this study were mainly acquired from the NOAA Comprehensive Large Array-Data Stewardship System (CLASS; http://www.class.noaa.gov) with the level 1B format (Kidwell 1998). The digital counts were converted into radiances through calibration coefficients saved in the data, which were then converted into the brightness temperatures (BTs) using the channel central wavenumbers.

Figure 3 displays global SSU pentad BT anomalies from the original SSU measurements respective to the NOAA-14 1995-2005 mean (hereafter, unless otherwise specified, all the SSU BT anomaly time series use the NOAA-14 1995-2005 climatology). Note that each SSU pixel has a $10^{\circ}$ instantaneous field of view (IFOV) with a ground resolution of $147 \mathrm{~km}$ at near nadir, and each scan line comprises eight individual pixels. These pixel observations were binned into grid cells of $2.5^{\circ}$ latitude by $2.5^{\circ}$ longitude resolution within a 5 -day interval (limb and diurnal corrections have not been applied yet at this stage) and then averaged. The area-weighted global mean was then calculated from these gridded pentad data. The SSU data time series in Fig. 3 indicate that SSU instruments provide a continuous measurement from October 1978 to May 2006 for channels 1 and 2 and January 1980 to May 2006 for channel 3 (SSU channel 3 on TIROS-N had a noise issue and the data are hence excluded from the time series). In addition, all three channel time series are punctuated by transient warming 
events associated with the large volcanic eruptions of El Chichón (1982) and Mt. Pinatubo (1991), which persisted for approximately two years. On the other hand, intersatellite biases apparently exist in the measurements from different satellites, resulting in ambiguity in time series. The worst case is $N O A A-7$ channel 2, which has a BT bias drift of up to $9 \mathrm{~K}$ relative to other satellites. Another challenge is that there is no overlap between NOAA-9 and NOAA-11 measurements, making their cross-calibration impossible. Overall, Fig. 3 demonstrates that the original SSU data from the existing calibration are not suitable for climate studies and thus adjustments have to be made.

The main steps of SSU data processing include 1) correcting the SSU BTs to those corresponding to identical weighting functions by removing gas leakage effects in the instrument $\mathrm{CO}_{2}$ cell and atmospheric $\mathrm{CO}_{2}$ increasing effect, 2) adjusting off-nadir SSU observations to nadirlike observations, 3) removing diurnal sampling biases due to satellite orbital drift, 4) gridding adjusted SSU BTs, and 5) statistical merging from different satellites. The final goal is to generate gridded nadirlike SSU BT measurements that correspond to identical weighting functions with the same local observation time.

\section{a. Orbital swath data correction}

As the first step, SSU orbital swath data are corrected to remove the respective biases mentioned above. Theoretically, the corrected SSU BTs with consistent weighting functions, the same observation viewing angle, and identical observational time can be expressed as

$$
T_{b c}=T_{b}-C_{1}-C_{2}-L-D,
$$

where $T_{b c}$ and $T_{b}$ are the corrected and original unadjusted SSU BTs, respectively; $C_{1}$ represents the BT changes due to the changing instrument cell pressure resulting from the $\mathrm{CO}_{2}$ gas leaking in the instrument cell, $C_{2}$ the BT changes caused by increases of atmospheric $\mathrm{CO}_{2}$ concentration, $L$ the $\mathrm{BT}$ adjustment due to viewing angle differences, and $D$ the diurnal correction. The assumption underlying Eq. (1) is that these correction terms are all uncorrelated, though the situation is much complicated in the real world.

We use the Community Radiative Transfer Model (CRTM; Han et al. 2006; Chen et al. 2011) simulations to estimate these correction terms. Developed recently at the Joint Center for Satellite Data Assimilation (JCSDA), the CRTM SSU model can well handle the varying cell pressures and atmospheric $\mathrm{CO}_{2}$ concentration (Chen et al. 2011). Validation studies indicate that the simulated BTs from the CRTM SSU model agree well with observation from the Microwave Limb Sounders
(MLS) and the Sounding of the Atmosphere using Broadband Emission Radiometry (SABER; Liu and Weng 2009; Chen et al. 2011).

The temperature profile along each SSU pixel is needed to estimate the correction terms by the CRTM. We rely on climate reanalyses to provide these temperature profiles. After reviewing all reanalysis datasets currently available, we chose the NASA Modern Era Retrospective Analysis for Research and Applications (MERRA; Rienecker et al. 2011) to provide the needed atmospheric profiles. MERRA uses the Goddard Earth Observing System version 5 (GEOS-5) atmospheric model that is coupled with the grid-point statistical interpolation (GSI) analysis scheme. The 72 vertical levels in GEOS-5 extend from the surface through the top stratosphere (the top level is $0.01 \mathrm{hPa}$ ), providing necessary height for the CRTM to achieve sufficient accuracies for SSU simulations. MERRA data are available from 1979 to present, covering the entire SSU observations. Compared to the newly developed National Centers for Environmental Prediction Climate Forecast System Reanalysis (CFSR), which suffers large spurious variability in the stratosphere temperature time series associated with the transitions between different computing streams (Long et al. 2009), MERRA has much less variability during satellite and stream transition periods (see Fig. 16 of Rienecker et al. 2011). Note that both SSU and subsequent AMSU observations have been directly assimilated into the MERRA analysis.

There is a concern that uncertainties in the MERRA reanalysis may cause uncertainties in the corrections. However, after adjustment method is described, we will show that accuracies in the corrections are much less sensitive to the uncertainties of the temperature profiles themselves. Instead, they are sensitive to the temperature differences between different layers. The uncertainties of the layer temperature differences are much smaller than those of the temperature itself. Thus, the corrections will not be very sensitive to the selections of different reanalysis systems.

The 27-yr (1978-2006) temperature, water vapor, and ozone profiles from MERRA are interpolated into the time and locations of the SSU pixel observations using a bilinear interpolation method and are used as inputs in the CRTM simulations. To assess the impacts of each step's correction on the SSU observations, the CRTM simultaneously simulates four sets of BT values from the interpolated profiles with different instrument cell pressures, atmospheric $\mathrm{CO}_{2}$ concentration, and scan angles. These include (1) BT1 for actually monitored instrument cell pressure values (shown in Fig. 3a), actual atmospheric $\mathrm{CO}_{2}$ concentration, and each pixel's real scan angle; (2) BT2 with fixed cell pressures but with actual 
$\mathrm{CO}_{2}$ concentration value and real scan angle; (3) BT3 for fixed instrument cell pressure values and fixed $\mathrm{CO}_{2}$ concentration but real scan angle, and (4) BT4 with fixed cell pressure values, fixed $\mathrm{CO}_{2}$ concentration value, and zero scan angle (like nadir pixels). ${ }^{1}$

Throughout this study, the fixed cell pressure values are chosen as 110, 40, and $15 \mathrm{hPa}$ for SSU channels 1, 2 and 3, respectively (dashed lines in Fig. 3a). These chosen values are different from the prelaunch specifications $(100,35$, and $10 \mathrm{hPa}$, respectively, for the three SSU channels) (Kidwell 1998) but closer to the multiyear means of different satellites. The fixed $\mathrm{CO}_{2}$ concentration is $330 \mathrm{ppmv}$, which is the value near the early 1980s.

The differences of the above-simulated BTs are used to estimate how the SSU BT changes due to the change of instrument cell pressure, atmospheric $\mathrm{CO}_{2}$ concentration, and observation viewing angles. Specifically, the correction terms at each pixel in Eq. (1) are expressed as

$$
\begin{aligned}
& C_{1}=\mathrm{BT} 1-\mathrm{BT} 2, \\
& C_{2}=\mathrm{BT} 2-\mathrm{BT} 3,
\end{aligned}
$$

and

$$
L=\mathrm{BT} 3-\mathrm{BT} 4 .
$$

Note that the correction terms of $C_{1}, C_{2}$, and $L$ are assumed to be independent of each other.

The real atmospheric $\mathrm{CO}_{2}$ concentration values are taken from the $\mathrm{CO}_{2}$ monthly mean measurements at Mauna Loa Observatory, Hawaii (Thoning et al. 1989), obtained online (available at http://www.esrl.noaa.gov/ $\mathrm{gmd} / \mathrm{ccgg} /$ trends/). We have compared it with the global mean $\mathrm{CO}_{2}$ dataset, which were derived by averaging the observations over several marine surface sites (Masarie and Tans 1995). The trend of their difference is very small $\left(\sim 0.02 \mathrm{ppmv} \mathrm{yr}^{-1}\right)$, despite some differences in the amplitude of the annual cycle $(\sim 0.4 \%)$. Given that the global mean $\mathrm{CO}_{2}$ dataset begins from January 1980 and does not fully cover the SSU time series (start from October 1978), we opt for the $\mathrm{CO}_{2}$ observations at Mauna Loa Observatory. When the CRTM simulates the SSU measurements, the atmospheric $\mathrm{CO}_{2}$ is assumed uniformly distributed in space and well mixed vertically, though there is evidence that the atmospheric $\mathrm{CO}_{2}$ concentration is neither spatially homogeneous (e.g., Chahine et al. 2008) nor vertically uniform from the troposphere to the stratosphere (e.g., Anderson

1 The Met Office routinely monitored and recorded the mean cell pressure at six-month intervals after the launch of each spacecraft.
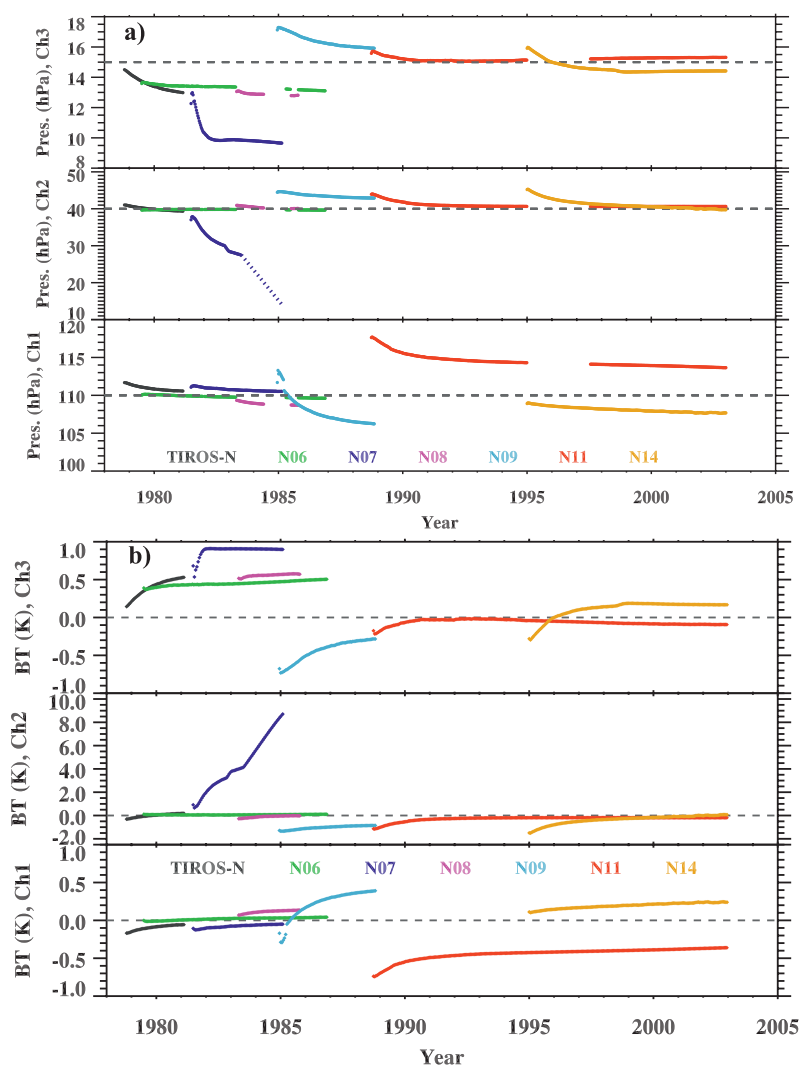

FIG. 4. (a) Ten-day time series of cell pressures for SSU channels 1,2 , and 3 of all SSU instruments as a function of time, where the dashed lines indicate the values of 110,40 , and $15 \mathrm{hPa}$ and the dotted line in NOAA-7 (N7) channel 2 represents the values predicated by CRTM (Chen et al. 2011). (b) CRTM-simulated BT anomaly time series relative to those using constant cell pressures (indicated by the dashed lines). The standard atmospheric profile with constant atmospheric $\mathrm{CO}_{2}$ concentration (330 ppmv) and time-varying cell pressure records shown in (a) are used in the simulation.

et al. 1996). However, since the observed stratospheric $\mathrm{CO}_{2}$ growth rate generally follows closely the observed growth rate at the earth surface (Boering et al. 1996), this assumption does not significantly impact the final analysis because we focus on temperature anomalies. After the above steps, the SSU BTs have been converted to the nadir-view observations with identical weighting functions. In the following subsections, we show how each correction affects the SSU measurement time series.

\section{1) Cell pressure CORRection}

Figure 4a shows the 10-day time series of cell pressures for the three SSU channels for all satellites, which were interpolated from the Met Office's six-monthly cell pressure data records (Kobayashi et al. 2009). Owing to gas leakage in the $\mathrm{CO}_{2}$ cell, the cell pressure of a given satellite gradually (e.g., NOAA-14) or sharply (e.g., 


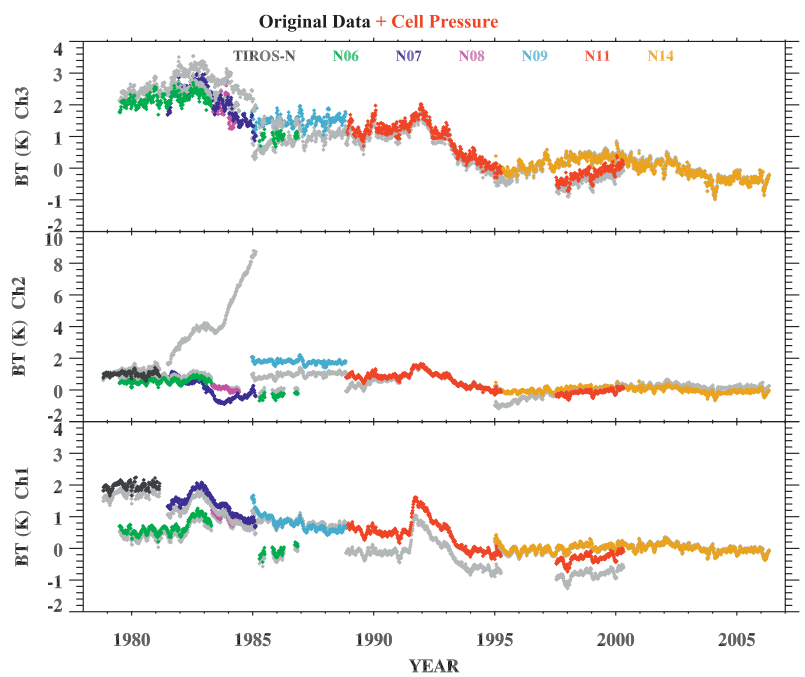

FIG. 5. As in Fig. 3 but before (gray) and after (color) instrument cell pressure correction.

channel 3 of $N O A A-7)$ decreased after launch and then reached a relatively constant level. As a result, the levels of peak energy for the SSU channels were affected by changes of instrument cell pressures. To illustrate how the cell pressure changes affect the measured BT, we simply use the standard atmospheric temperature profile and the constant atmospheric $\mathrm{CO}_{2}$ amount in the CRTM simulations but with varying cell pressure records as shown in Fig. 4a. As a result, the BT changes caused by the cell pressure changes, relative to those using constant cell pressures, are given in Fig. 4b. The figure indicates that the varying cell pressures introduce large timevarying signals into the SSU BT time series and differences in cell pressures are the major contributors to the intersatellite biases among SSU instruments.

The cell-pressure-induced BT changes are not only related to weighting function alteration but also depend on the stratospheric lapse rate at a given pixel. Figure 5 illustrates their combined effect on SSU pentad BT anomalies by adjusting the SSU observations to those with identical instrument cell pressures using relatively realistic atmospheric temperature profiles from MERRA. Among the three channels, channel 3 benefits most from this correction because, after the adjustment, measurements from different satellite were well linked together except for $N O A A-11$ and $N O A A-14$. For channel 2, after correction, the large BT drift of $N O A A-7$ is reduced to less than $0.5 \mathrm{~K}$ and the large biases between $N O A A-11$ and NOAA-14 (1995-96) disappear. For channel 1, the observations from $N O A A-11$ are brought together with $N O A A-9$ and NOAA-14, while intersatellite biases among TIROS-N, $N O A A-6$, and NOAA-7 still exist, indicating that other factors are relevant (e.g., radiometric calibration).

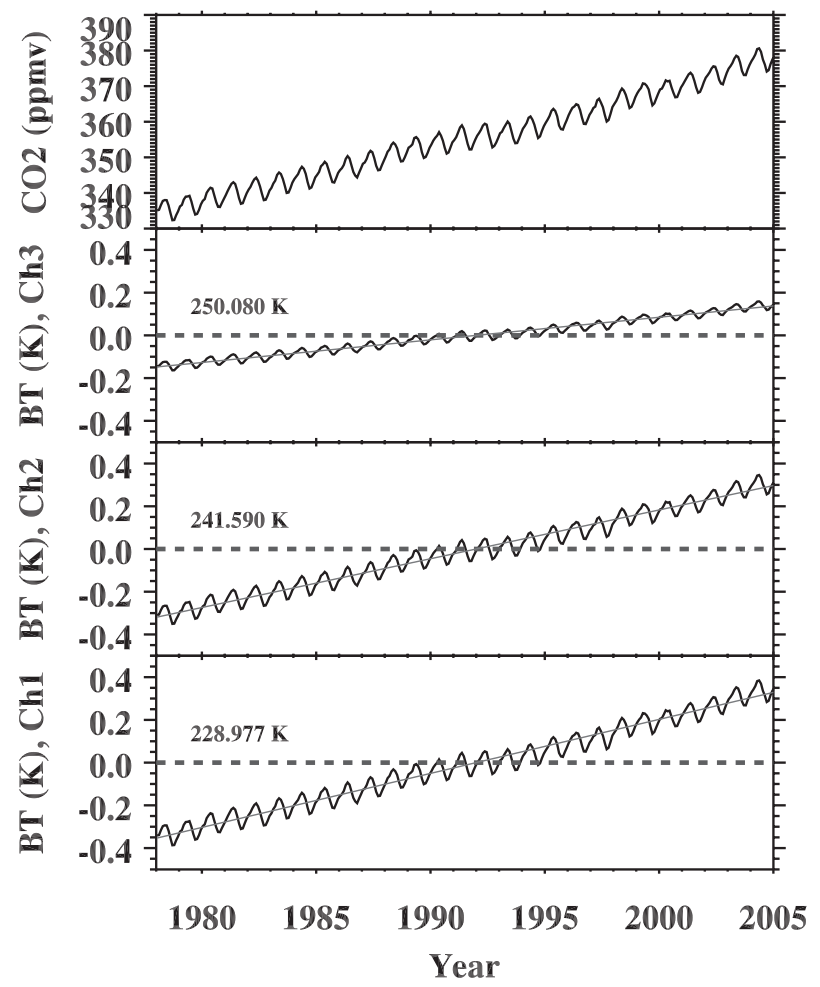

FIG. 6. (top) Monthly mean atmospheric measured at Mauna Loa Observatory, Hawaii, and CRTM simulated SSU BT changes relative to the mean (indicated by the dashed lines) using the standard atmospheric profile with constant cell pressure values but time-varying atmospheric $\mathrm{CO}_{2}$ concentration.

\section{2) AtMospheric $\mathrm{CO}_{2}$ CORRECTION}

The top panel of Fig. 6 shows the monthly mean atmospheric $\mathrm{CO}_{2}$ concentration measured at Mauna Loa Observatory, Hawaii, and the other three panels show the SSU BT changes (with respect to their mean) due to the varying atmospheric $\mathrm{CO}_{2}$ concentration simulated by the CRTM based on the U.S. Standard Atmosphere, 1976 profile with constant cell pressures. A previous study by Shine et al. (2008) suggested that increasing atmospheric $\mathrm{CO}_{2}$ would move peaks of the SSU weighting functions to higher altitudes. Since temperatures increase with height in the stratosphere, this would result in temperature trends to be warmer than the real trends. The results from Fig. 6 confirm this: linear positive trends are obtained due to the varying atmospheric $\mathrm{CO}_{2}$ concentration. The specific values for the trends are $0.25,0.23$, and $0.11 \mathrm{~K} \mathrm{decade}^{-1}$ for channels 1,2 , and 3, respectively, which are close to the calculations by Shine et al. Interestingly, the trend difference for channel 3 is smaller than those for channels 1 and 2 . The reason is that the weighting function of channel 3 includes contribution from the mesosphere where temperature decreases with height. Consequently, the increased temperature due to 


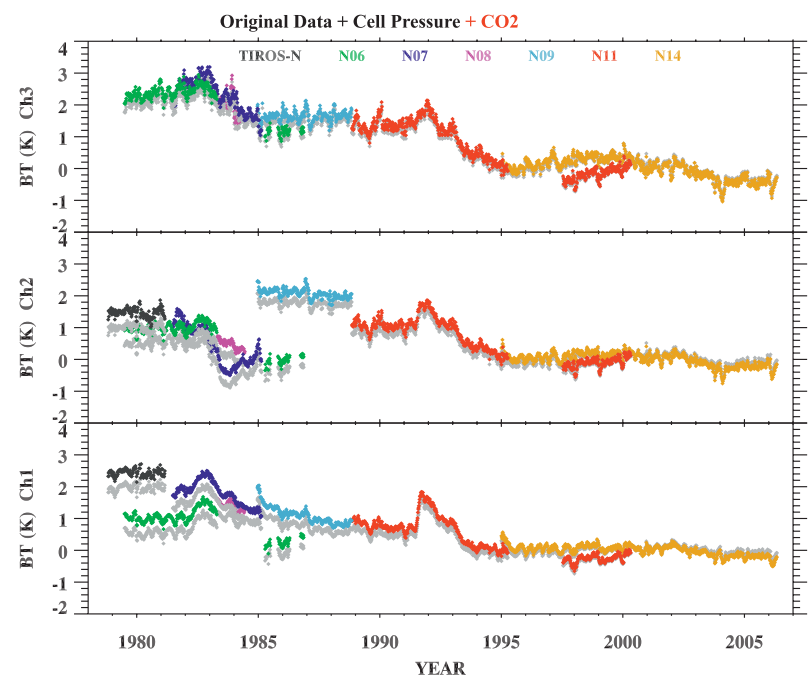

FIG. 7. As in Fig. 5 but before (gray) and after (color) atmospheric $\mathrm{CO}_{2}$ correction.

increasing atmospheric $\mathrm{CO}_{2}$ is partially canceled by contribution from the mesosphere.

Figure 7 gives the SSU BT anomalies before and after adding the correction to remove the effect of increasing atmospheric $\mathrm{CO}_{2}$. Since this correction removes the spurious warming trend overlaid on the SSU measurements, the resulting time series skew slightly down to the right direction compared to those before the adjustment, with channels 1 and 2 being more apparent than channel 3.

\section{3) LIMB CORRECTION}

The limb effect is caused by the increase in optical path as the instrument scans from near-nadir to larger angles, which causes the peak of the channel weighting functions to increase in altitude. Since the temperature increases with altitude in the stratosphere, the SSU measured BTs also increase with instrument scan angles. Recall that each SSU scan comprises eight $10^{\circ}$ IFOV observations; positions 4 and 5 have near-nadir angles of $5^{\circ}$, while positions 1 and 8 are at the extreme scan positions with scan angle of $35^{\circ}$. Using the CRTM to simulate the SSU observations through different view angles (for the U.S. Standard Atmosphere, 1976), we found that the BT differences between positions 1 and 4 can range from 1.0 to $1.5 \mathrm{~K}$ dependent on different channels.

After the limb correction, all the SSU observations will be adjusted to those with a zero viewing angle. Figure 8 gives the SSU BT anomaly time series after adding the limb correction, indicating that the BT anomalies do not change after the limb correction but their absolute values do decrease (see figures below).

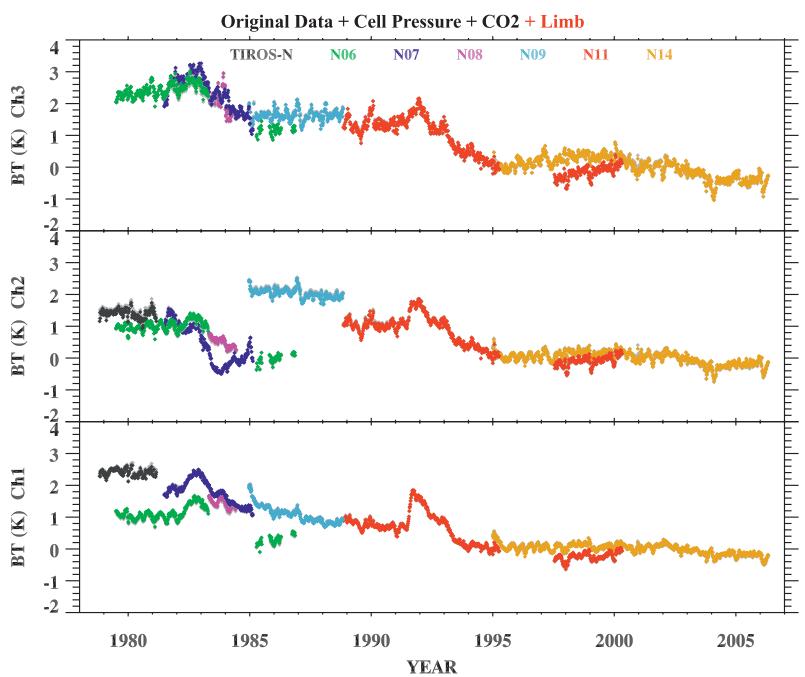

FIG. 8. As in Fig. 7 but before (gray) and after (color) limb correction.

\section{4) Changes in Seasonal CyCle Climatology}

In addition to the BT anomaly changes, it is worth examining how the 1995-2005 seasonal climatology changes when each correction is added (Fig. 9). Since the seasonal cycle climatology changes are close to a constant for different seasons for each correction addition (Fig. 9), its changing characteristics can be basically represented by an absolute BT mean value. As shown, with the cell pressure correction, the BT mean values decrease for channels 1 and 3 and increase for channel 2 . This is because the reference cell pressures chosen in this study are smaller for channels 1 and 3 and larger for channel 2 than the actual values of NOAA-14. With the atmospheric $\mathrm{CO}_{2}$ correction, the absolute BT mean values decrease for all three channels. The reason is that the reference value of atmospheric $\mathrm{CO}_{2}(330 \mathrm{ppmv})$ is smaller than the actual $\mathrm{CO}_{2}$ values in 1995-2005, resulting in weighting functions peaking lower in the stratosphere. When adding the limb correction, the absolute mean BT mean values became smaller owing to the fact that the observed BTs increase with the viewing angles. The diurnal correction as shown below slightly changes the pattern of the seasonal climatology with magnitudes increasing from channel 1 to channel 3 .

\section{5) IMPACTS OF ACCURACY OF ATMOSPHERIC PROFILES}

The adjustment procedure extensively uses the CRTM model simulations with MERRA reanalysis as inputs. The concern is how the accuracy of the MERRA stratospheric profiles affects the correction terms. As discussed in the above, all corrections are related to the changes of the weighting functions due to different factors, that is, 


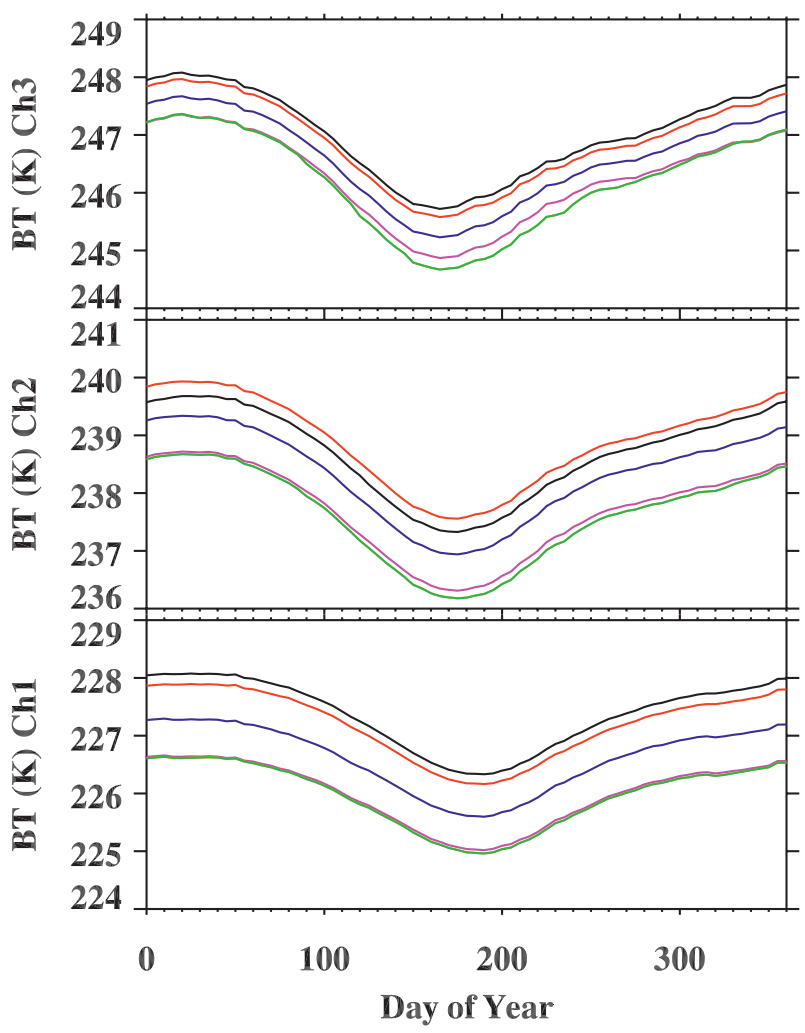

FIG. 9. Seasonal cycle climatology from global mean BTs for 1995-2005, used to remove seasonal variations for each correction step, including (a) original observations (black), (b) with cell pressure correction (red), (c) with cell pressure and $\mathrm{CO}_{2}$ correction (blue), (d) with cell pressure and $\mathrm{CO}_{2}$, and limb correction (pink), and (e) with cell pressure and $\mathrm{CO}_{2}$, limb, and diurnal correction (green)

changes of $\mathrm{CO}_{2}$ cell pressures, increasing atmospheric $\mathrm{CO}_{2}$, and different view angles. Therefore, the estimated correction terms, which are determined by changes of weighting functions, are sensitive to the layer temperature differences instead of the temperature profile itself. As an example, Fig. 10 shows the time series of modelsimulated SSU BTs using constant (gray) and actually monitored cell pressures (color) for NOAA-11 and $N O A A-14$ channel 2 [BT1 and BT2 in Eq. (2)]. Figure 10a shows that the simulated layer temperatures from the MERRA profiles do not quite catch variability of the real atmosphere. For example, the transient warming event associated with the volcanic eruptions of Mt. Pinatubo (1991) was not clearly captured by the simulation (compared to Fig. 3). In addition, the spurious temperature jumps near 1996 and 2000 (also shown in Fig. 16 of Rienecker et al. 2011) are apparently due to model errors. Despite these defects, time series of the correction term (Fig. 10b) that are calculated from the differences of the above two simulations do not contain the spurious variations and jumps related to the MERRA temperature

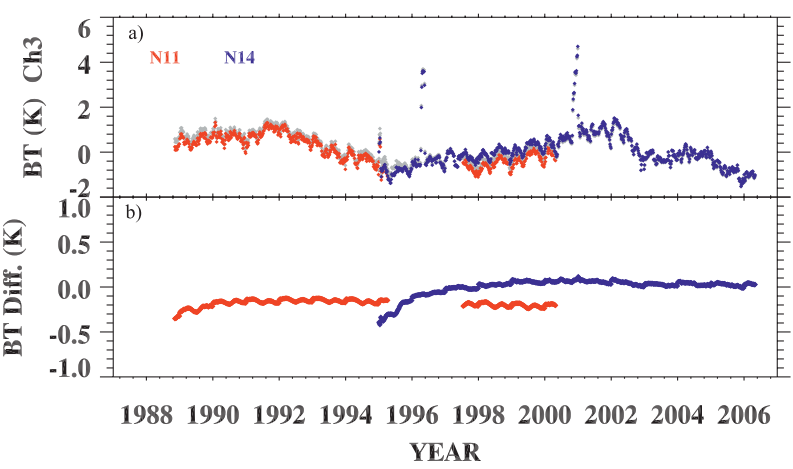

FIG. 10. Global mean time series of three variables in Eq. (2) for NOAA-11 and NOAA-14 channel 3: (a) BT1 (color) and BT2 (gray) and (b) their difference $C_{1}$.

profile. In fact, the correction time series in Fig. 10b is very similar to Fig. $4 \mathrm{~b}$ where standard atmospheric profiles were used to derive the correction terms. This experiment demonstrates that selections of different reanalysis systems may not be critical to the accuracy of the correction terms. In other words, the correction is robust even though there are obvious errors in the MERRA temperature profiles.

\section{b. Diurnal correction}

To derive the diurnal corrections for SSU observations, 10 years of MERRA monthly mean with grid resolution of $1.25^{\circ}$ latitude by $1.25^{\circ}$ longitude, 3 -hourly profiles from 2000 to 2010 are first averaged at each of its output hour to obtain a multiyear mean 3 -hourly profile. These yearlyaveraged profiles are then used in the CRTM to obtain simulated SSU observations with fixed instrument cell pressures, constant atmospheric $\mathrm{CO}_{2}$ concentration, and a zero scan angle. The diurnal cycle anomalies for the three SSU channels as a function of local time, month, latitude, and longitude were then derived by interpolating the simulated three-hourly SSU BTs into every hour during a day. We expect that the 2000-10 MERRA diurnal anomalies are more accurate than others since more observations from advanced instruments (such AMSU measurements) were assimilated in the reanalysis.

For each SSU pixel observation, the simulated diurnal anomalies closest to the time and location of the SSU pixels are used to derive the correction term,

$D=\mathrm{BT}(\mathrm{h}, \mathrm{mon}$, lat, lon $)-\mathrm{BT}(12, \mathrm{mon}$, lat, lon $)$,

where BT (h, mon, lat, lon) is the simulated SSU brightness temperature, $h$ the local standard time (LST) of the SSU pixel; mon, lat, and lon are the month, latitude, and longitude of the matched grid to the pixel. The above correction adjusts all SSU pixel observations to the 1200 LST. This method is similar to other studies on the High 


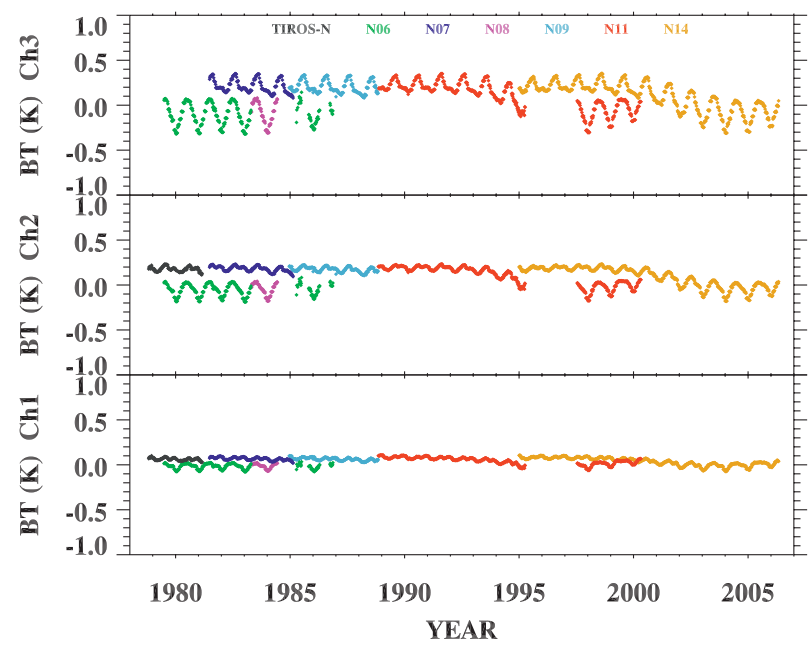

FIG. 11. Global mean of diurnal correction term.

Resolution Infrared Radiation Sounder (HIRS) and MSU instruments where model simulations were used to derive the diurnal anomalies (Mears et al. 2003; Dackson and Soden 2007; Zou and Wang 2010).

Figure 11 displays the global mean time series of the diurnal correction term for the SSU observations. Some interesting features are revealed. First, the values of corrections for the satellite drift are much smaller (less than $0.3 \mathrm{~K})$ than diurnal variations of the stratospheric temperatures found in the radiosonde observations $(\sim 1.5 \mathrm{~K}$ at $10 \mathrm{hPa}$; Seidel et al. 2005). Since the NOAA polarorbiting satellite passes over a given location twice daily in about 12-h interval between its ascending and descending orbits, the means of the ascending and descending measurements minimized the effect of the orbit drift and the atmospheric diurnal variation. Second, the correction is more important for recent satellites, particularly NOAA11 and $N O A A-14$. This is because they drifted more than half a day during their longer operational time, going through larger amplitude variations in diurnal cycles (Brownscombe et al. 1985; Nash and Forrester 1986). Figure 11 also shows that correction magnitude increases from channel 1 to channel 3, indicating that the diurnal amplitude of the stratospheric temperatures increase with altitude. From the physical point of view, this can be explained by the fact that the ozone absorption of ultraviolet radiation from the sun is a source of heat in the stratosphere, which is mainly confined in the upper stratosphere.

Figure 12 demonstrates the performance of the diurnal anomalies in correcting the diurnal drift errors by showing the spatial distribution of the channel 3 intersatellite BT biases between $N O A A-7$ and $N O A A-8$ for their overlapping period before and after the diurnal corrections. It is seen that the intersatellite bias is greatly reduced in the tropics and Northern Hemisphere. However, BT biases became larger over the Antarctica after the correction, suggesting that the MERRA based diurnal anomalies are not reliable over this region and these biases have to be removed through the statistical merging in the next step.

\section{c. Statistical merging}

After the above steps, the orbital SSU observations are corrected to those with consistent weighting functions, zero viewing angle, and identical local observational time. Figure 13 shows the BT anomalies time series after all of these corrections. Nevertheless, intersatellite biases still exist for channels 1 and 2 for certain satellite pairs. We suspect that these remaining biases are caused by inaccurate instrument calibration. For example, while the observations among NOAA-7, $-8,-9$, and -11 seemed consistent to each other in channel 1 , the intersatellite biases still existed among TIROS-N, NOAA6 , and the series from NOAA-7, $-8,-9$, and -11 . Nash and Forrester (1986) reported possible radiometric calibration
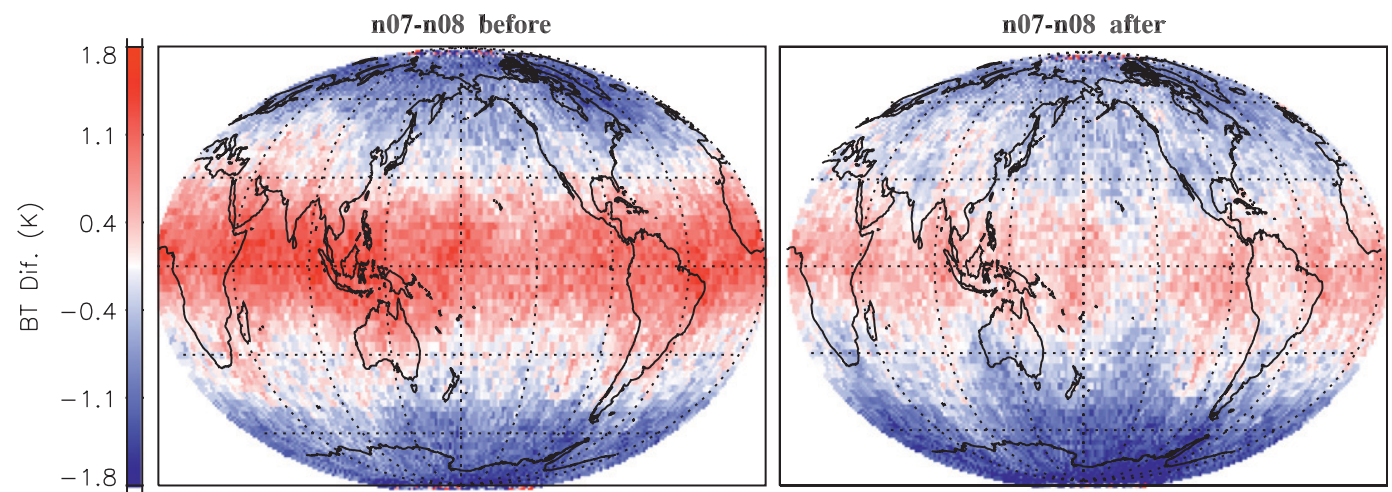

FIG. 12. Spatial distribution of SSU channel-3 intersatellite biases between $N O A A-7$ and $N O A A-8$ (left) before and (right) after diurnal corrections. 


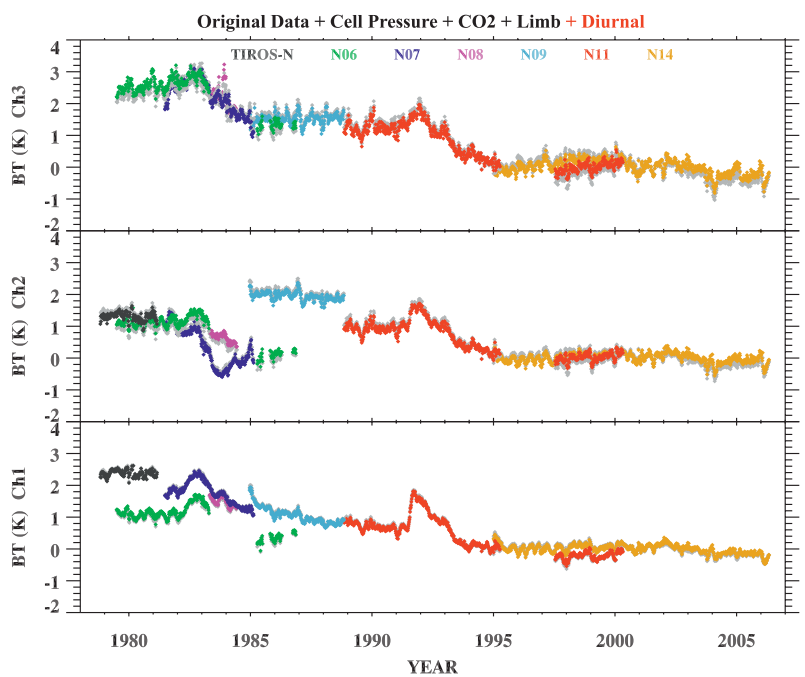

FIG. 13. As in Fig. 8 but before (gray) and after (color) diurnalsampling correction.

bias existing for $N O A A-9$ in channels 1 and 2 when comparing $N O A A-9$ with $N O A A-6$. Given the fact that there was lack of an on-orbit absolute standard for stratospheric temperature measurements, it is hard to decide which satellite measurements were the root causes of these differences. Therefore, statistical merging is needed to combine the observations from different satellites for trend analysis. Our strategy is to create consistent time series for trend analysis that have constant biases relative to the "truth." However, we should point out that the absolute calibration is still an unresolved topic and should be addressed in future studies.

First, a reference instrument is chosen to serve as the baseline instrument. Ideally, the instrument that is better calibrated than others should be chosen as an unbiased reference instrument. However, we have no such knowledge a priori, NOAA-14 is thus arbitrarily assumed as a reference satellite in this study, partly because it has a longer operational time and is closer to present, having the advantage that it can be verified by more recent Global Positioning System (GPS) Radio Occultation ( $\mathrm{RO})$ observations in the future. The assumption implies that, when we merge the SSU measurements, observations from NOAA-14 are assumed as the truth and are not changed, while those from other satellites are adjusted to fit with observations from $N O A A-14$. This assumption changes the absolute values of BTs from satellites other than NOAA-14 but should not affect the anomaly trend estimates according to previous studies (Zou and Wang 2010).

Second, a grid-cell-dependent constant bias correction method, which was used in the MSU dataset development by Zou et al. (2009), is employed to merge the observations. Specifically, a constant bias is derived at each grid cell by calculating the mean of their BT differences during their overlapping observations. For each grid cell, the constant bias is applied to the entire time period of a satellite for different satellites to fit each other.

Third, a big challenge is to merge the observations of $N O A A-9$ and NOAA-11 because there is no overlap between these two satellites. Shown in Fig. 9, fortunately, the observations from NOAA-9 and NOAA-11 in channels 1 and 3 are already linked to each other with only small differences existing between them. Therefore, when we merge the SSU dataset for channels 1 and 3, the observations from NOAA-9 and NOAA-11 are treated as observations from the same satellite. Any adjustments applied to the NOAA-11 (NOAA-9) measurements are automatically applied for NOAA-9 (NOAA-11).

On the other hand, a different scenario is shown for channel 2, where a large intersatellite bias exists between $N O A A-9$ and $N O A A-11$. We use a double-differencing method to estimate the intersatellite biases for this channel. Similar methods have been used to estimate the intersatellite biases between instruments on different satellites (e.g., Strow et al. 2008; Wang et al. 2010). Ideally, if we know the measured BT departures from an absolute truth for NOAA-9 and NOAA-11, their differences can be used to estimate the intersatellite biases under a constant intersatellite bias assumption; that is,

$$
\Delta T_{N 11-N 9}=\left[\left(O_{N 11}-\mathrm{TR}_{N 11}\right)-\left(O_{N 9}-\mathrm{TR}_{N 9}\right)\right]_{\text {mean }},
$$

where $O$ is the observed SSU BT after corrections, and TR is an assumed truth. We use CRTM model simulation $M$ plus an unknown model bias $\Delta M$ to represent the truth and then substitute TR in Eq. (6) by $M+\Delta M$. The quantity $M$ is taken as $1-y r$ CRTM simulations before and after the connection point between NOAA-9 and $N O A A-11$. These model simulations only change with atmospheric conditions but not with instruments since the same instrument parameters are used in the simulation. Assuming that the model bias $\Delta M$ is a constant in the two simulation periods, Eq. (6) becomes

$$
\Delta T_{N 11-N 9}=\left\{\left(O_{N 11}-M_{N 11}\right)-\left(O_{N 9}-M_{N 9}\right)\right\}_{\text {mean }},
$$

where $M_{N 9}$ and $M_{N 11}$ represent the model simulations overlapping with $N O A A-9$ and $N O A A-11$, respectively. Essentially, this double-differencing method uses model simulation as a common reference. Our results indicate that it provides a reasonable estimate of the NOAA-9 and NOAA-11 intersatellite biases in channel 2 . 

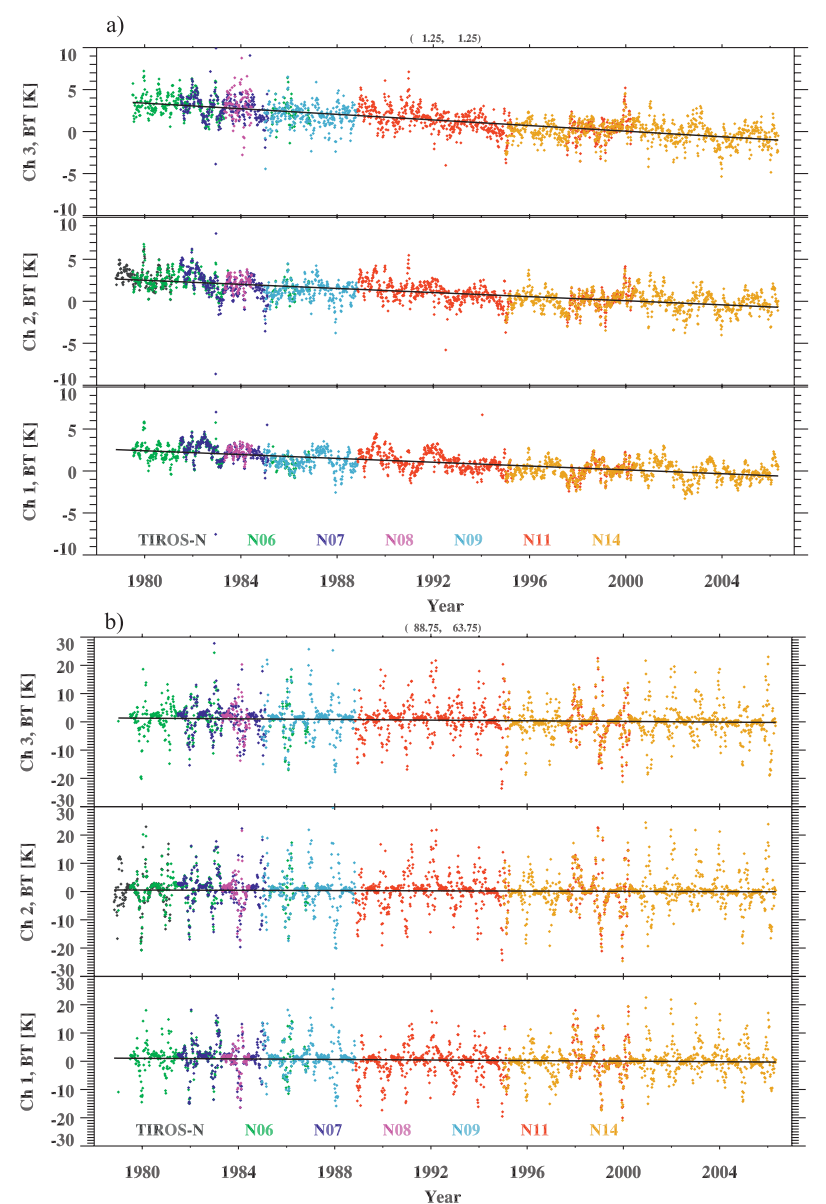

FIG. 14. Merged time series from different satellites at the grid cell (a) $1.25^{\circ} \mathrm{N}, 1.25^{\circ} \mathrm{E}$ and (b) $63.75^{\circ} \mathrm{N}, 88.75^{\circ} \mathrm{E}$.

Figure 14 shows the merged time series from different satellites at two arbitrarily chosen grid cells $\left(1.25^{\circ} \mathrm{N}\right.$, $1.25^{\circ} \mathrm{E}$ and $63.75^{\circ} \mathrm{N}, 88.75^{\circ} \mathrm{E}$, respectively). The first site represents a tropical time series with relatively smaller variation, while the second point represents sites with larger variations at the polar regions. Both figures indicate that there are no obvious discontinuities during satellite transition period, so the time series from different satellites are combined together satisfactorily and linear trend lines can be derived from them. From the merging point of view, the confidence in the tropical trends should be higher than those in the polar regions due to larger temperature variations in the polar regions than in the tropics.

\section{Trend results}

\section{a. Merged time series}

After all corrections, global stratospheric temperature data records are generated on $2.5^{\circ} \times 2.5^{\circ}$ grids that

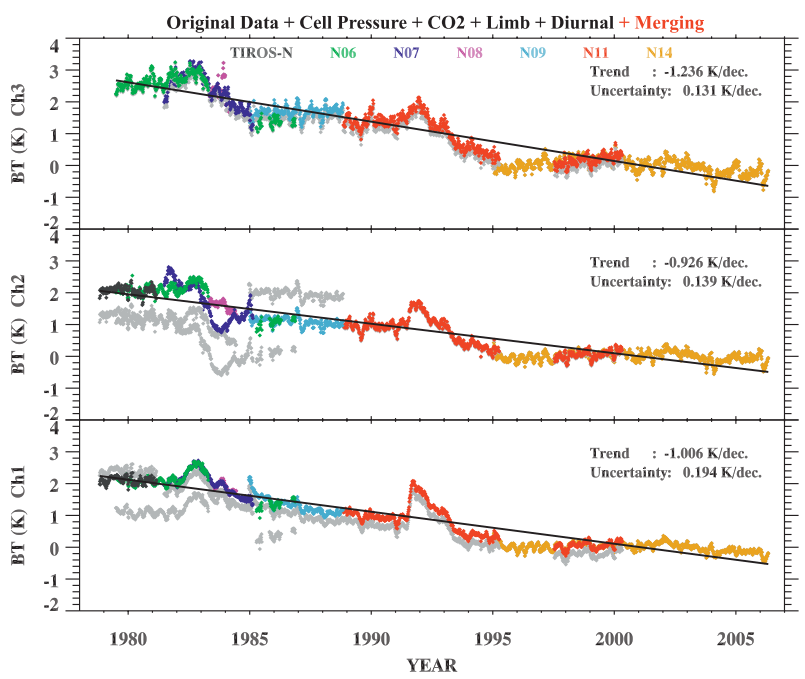

FIG. 15. As in Fig. 13 but before (gray) and after (color) merging of different satellite measurements. The linear trends and $95 \%$ confidence intervals are derived from single time series by averaging the measurements from different satellites.

correspond to identical weighting functions with the same observation time and zero view angles. From the nature of their weighting functions as shown in Fig. 1, the time series from the three SSU channels represent layer temperatures of the midstratosphere (TMS, channel 1), upper stratosphere (TUS, channel 2), and top stratosphere (TTS, channel 3). Global mean anomaly time series and trends for these three layer temperatures are shown in Fig. 15. For channels 1 and 3, the correction and merging procedures work well, reflected by time series of different satellites being close to each other. For channel 2, $N O A A-7$ still has noticeable biases relative to NOAA-8. This is because the cell pressure values of NOAA-7 channel 2 were missing after June 1983 (see Fig. 4a). Consequently, CRTM has to predict these values using linear regression (Chen et al. 2011). Although the predicted values have greatly reduced the NOAA-7 biases, they are not accurate enough to correct all the biases because of the $\mathrm{CO}_{2}$ cell leakage. As a result, the observations from NOAA-7 channel 2 before May 1984 are not used for the final dataset.

\section{b. Linear trend}

Based on the data used in Fig. 15, a single time series is produced by averaging the measurements on different satellites. Anomaly time series is further derived by removing the 1995-2005 seasonal climatology. The straight lines in Fig. 15 are the anomaly linear trends of the single SSU time series. To estimate uncertainties of the trends, we follow the method proposed by Santer et al. (2000). First, the lag-1 autocorrelation coefficients are calculated from the linear regression residuals, 
which are then used to derive the effective sample size by accounting for temporal autocorrelation in the time series. Second, two-sigma confidence intervals (95\% confidence level) are determined based on the above effective sample size, which are listed together with the trend values in Fig. 15.

Overall, all three SSU channels show a significant cooling trend of the stratospheric temperature over 19792006, but the changes were not monotonic. The signature of the El Chichón (1982) and Pinatubo (1991) volcanic eruptions are seen as transient warming in all three SSU channels. Mean temperatures following each volcanic warming episode were lower than before the eruption, which may be caused by the fact that superimposed persistent temperature trends were interrupt by the volcanic warming. Small or neutral temperature trends for the most recent decade 1995-2006 are found for all three channels. The similar feature has also been revealed by the combined MSU/AMSU observations in channel 4, which sense the temperature in the lower stratosphere ( $\sim 80 \mathrm{hPa})$ (Zou and Wang 2010). Among the three SSU channels, based on the five-day global time series, the largest trends are observed in the top stratosphere (channel 3 ) with values of $-1.236 \mathrm{~K} \mathrm{decade}^{-1}$. For channels 1 and 2, the trend values from this study are $-1.006 \mathrm{~K} \mathrm{decade}^{-1}$ and $-0.926 \mathrm{~K} \mathrm{decade}^{-1}$, respectively.

The latitudinal distribution of the linear trends for three SSU channels is given in Fig. 16. Overall, for all three channels substantial annual-mean cooling is revealed in the tropical stratosphere. In contrast, the temperature trends are somewhat weaker in high latitudes, while all three channels have smallest cooling trends in the southern polar region. In addition, relative cooling minima can be found near $40^{\circ} \mathrm{N}$ in channels 2 and 3. This tropical stratosphere enhanced cooling structure has been reported in previous studies. For example, the trend from MSU channel 4, which measured the layer temperature at lower stratosphere $(\sim 80 \mathrm{hPa})$, also revealed a similar feature (Zou et al. 2009; Fig. 9). Using the radiosonde datasets, Thompson and Solomon (2005) found widespread annual mean cooling of the tropical lower stratosphere. The trends are substantial and statistically significant at nearly all radiosonde stations throughout a broad region extending from $\sim 40^{\circ} \mathrm{S}$ to $\sim 40^{\circ} \mathrm{N}$, while the temperature trends are somewhat weaker and less significant at most stations in middle latitudes. Lanzante et al. (2003) found a similar feature in trends based on adjusted radiosonde data at levels above $100 \mathrm{hPa}$ for the period 1959-97 and above $50 \mathrm{hPa}$ for the period 1979-97. While the composition of the stratosphere (i.e., ozone and $\mathrm{CO}_{2}$ ) plays an important role in global-mean stratospheric temperature trends (Ramaswamy et al. 2001; Shine et al. 2003), this meridional structure of
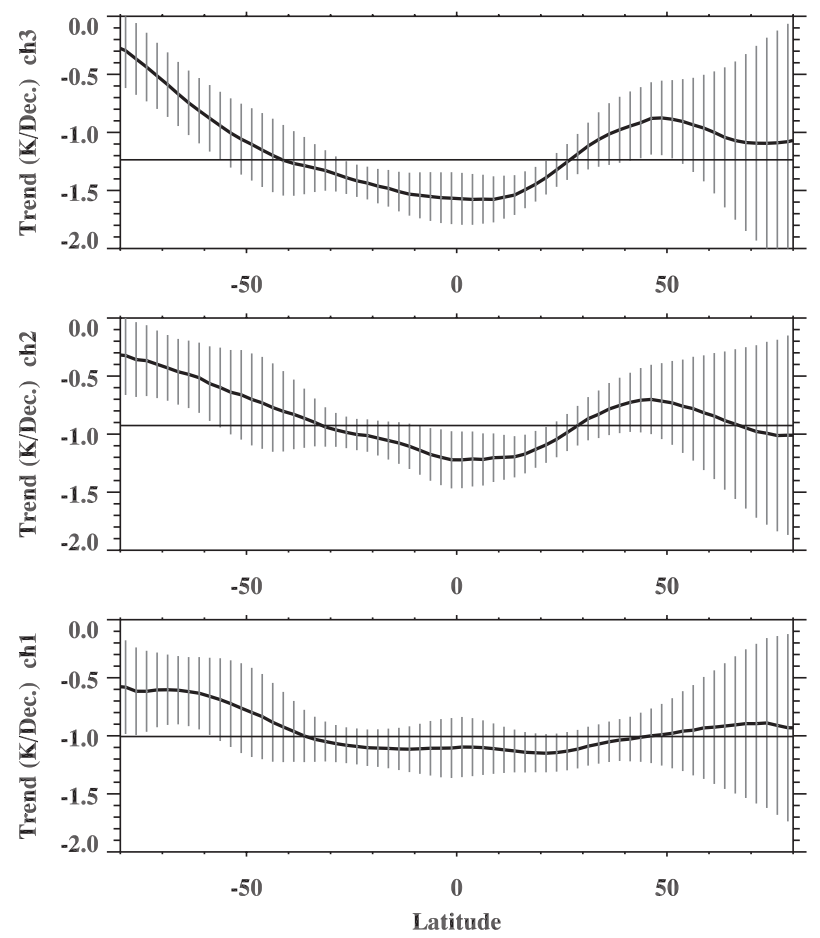

FIG. 16. Latitudinal structures of the linear trends of SSU BT anomalies for the three SSU channels. The vertical bars represent $95 \%$ confidence intervals and the horizontal lines indicate the global mean trends.

the stratospheric temperature trends revealed from this SSU dataset may be attributed to the acceleration of the stratospheric Brewer-Dobson circulation (BDC) under rising concentrations of greenhouse gases (e.g., Garcia and Randel 2008), that is, adiabatic cooling driven by enhanced upwelling in the tropical stratosphere. By examining the seasonality of tropical lower-stratospheric temperature trends using the MSU lower-stratospheric channel (T4) for 1980-2008, Fu et al. (2010) and Lin et al. (2009) suggested that this seasonality is largely a response to BDC changes driven by extratropical wave forcing.

Finally, Fig. 17 gives the spatial distribution of trends for the three layer temperatures, where the red lines indicate the global mean trend values. It is consistent with Fig. 16, showing that the enhanced net cooling is located in the tropics and it becomes larger from the midstratosphere to the top stratosphere. Smaller cooling regions are found in the southern polar region. In the Arctic relative minima and maxima of net cooling coexist, illustrating a stratospheric wave-1 pattern.

\section{c. Comparison with the Nash dataset}

It is of interest to compare our newly developed SSU time series to the existing Nash SSU dataset to understand impact on trends due to different data construction methods. Three nadir channels from the Nash 

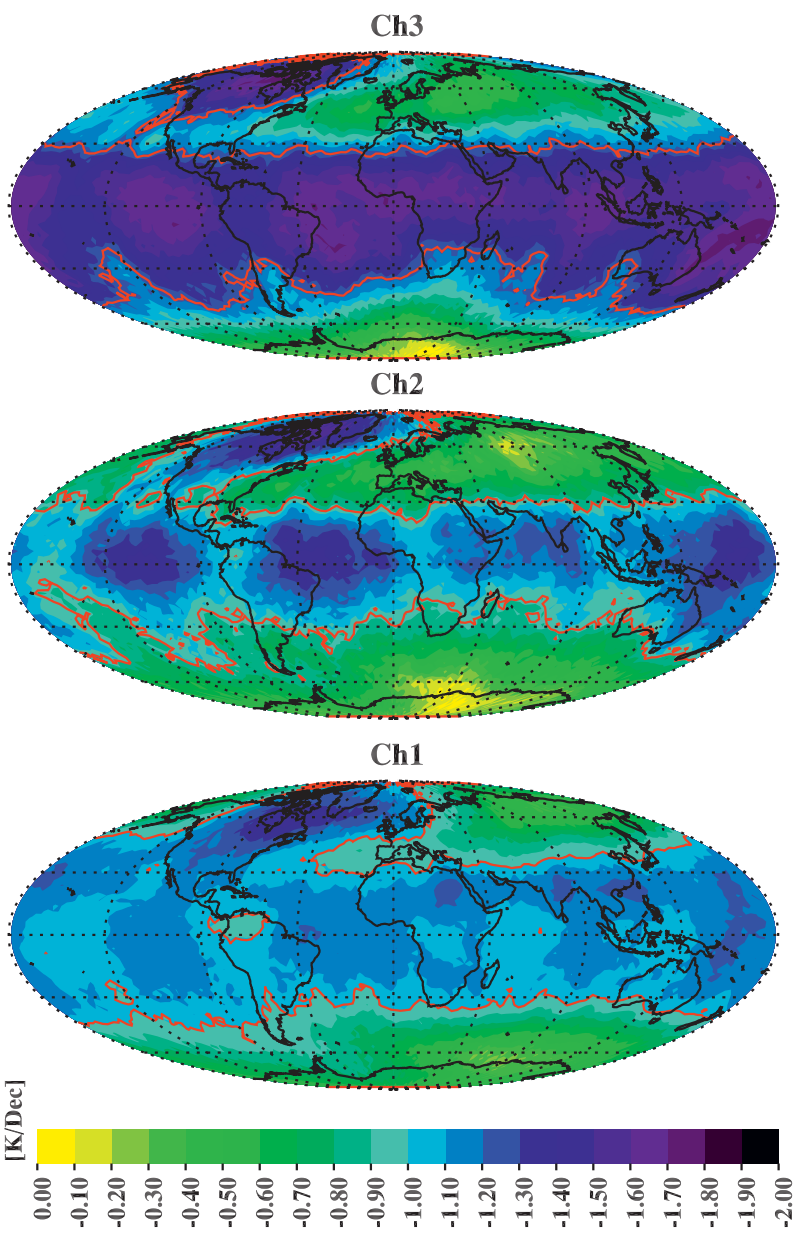

FIG. 17. Spatial distributions of the linear trends for three SSU channels. The red lines indicate the global mean trends.

dataset that contain two near-nadir pixels with a view angle of $5^{\circ}$ are chosen for comparison. The dataset can be obtained from either the Climate Prediction Center in the NOAA National Centers for Environmental Prediction or the data center of the Stratospheric Processes and their Role in Climate (SPARC) project.

As already noted above, Nash SSU data are available as monthly zonal mean temperature anomalies on a $10^{\circ}$ latitude grid covering $70^{\circ} \mathrm{N}$ to $70^{\circ} \mathrm{S}$ from January 1979 to December 2005. To make a valid comparison, we converted the NOAA pentad gridded SSU data to the same format as Nash's dataset, namely monthly zonal means in every $10^{\circ}$ interval from $70^{\circ} \mathrm{S}$ to $70^{\circ} \mathrm{N}$, which was then cut off from January 1979 to December 2005. Since the weighting functions from the two datasets are almost identical except for small differences in channel 2 and 3 , the two datasets should be comparable after the conversion. Note that only three SSU original channels are compared. Finally, we should point out that the data sampling is quite different for two datasets; that is, we use

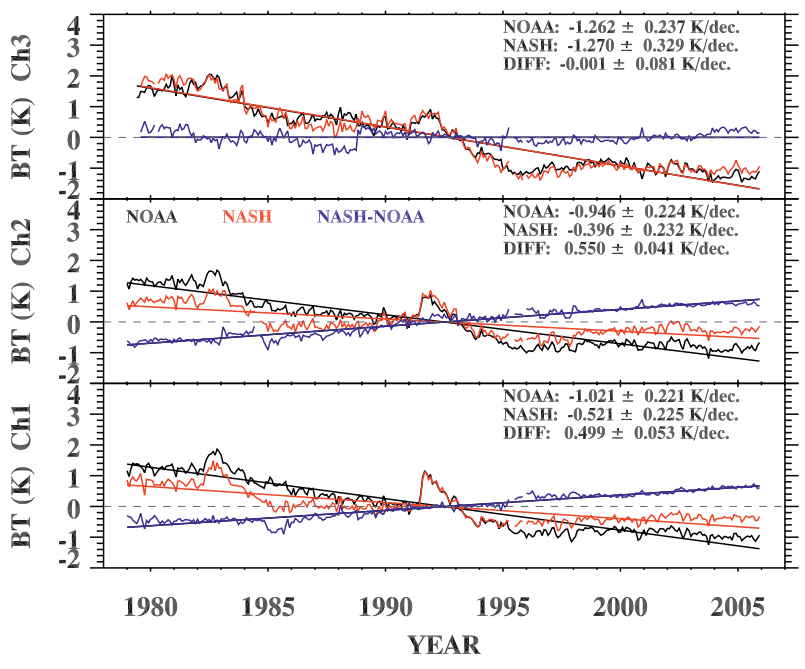

FIG. 18. Global stratospheric temperature anomaly time series for SSU channels 1,2, and 3 from this study (black) and the Nash dataset (red) as well as their differences (blue). The anomalies are relative to the 1979-2005 mean of each dataset. Linear trends with 95\% confidence intervals (with autocorrelation adjustments) are also listed.

all of the SSU pixels (eight pixels from $-35^{\circ}$ to $35^{\circ}$ ) but Nash only utilizes nadir scans $\left(5^{\circ}\right.$ only).

Figure 18 shows the global mean anomalies for the two datasets, each computed with respect to their own 1979-2005 climatology. The difference of the two anomaly time series is also calculated and shown in the figure. The channel 3 trends of the two datasets are nearly identical, being $-1.262 \mathrm{~K} \mathrm{decade}^{-1}$ for ours (NOAA) versus $-1.270 \mathrm{~K} \mathrm{decade}^{-1}$ for Nash's. This occurs possibly because there were relatively smaller intersatellite biases in channel 3 (see Fig. 3), the correction procedures for channels 3 did not significantly change the original measurements, resulting in consistencies between the two datasets. On the other hand, the trends in channels 1 and 2 are quite different and the cooling trend in this study is much larger than for the Nash dataset. Of interest, the difference time series between NOAA and Nash datasets (Nash minus NOAA) exhibit linear trends as large as $\sim 0.5 \mathrm{~K} \mathrm{decade}^{-1}$ for channels 1 and 2 . While the variability between the two time series is generally consistent to each other, the differences can be found during 1986-90 for channel 3 and after the volcanic eruption of El Chichón for channels 1 and 2 (1985-86). These different trends may be caused by the different merging approaches. Nash and Forrester (1986) showed that the merging was done in the earlier period of the Nash dataset, but it is not clear whether similar procedures were applied in the later period. However, as we mentioned in the introduction, data processing details on Nash dataset were not well documented, so it is hard to further explore the causes of these differences. 

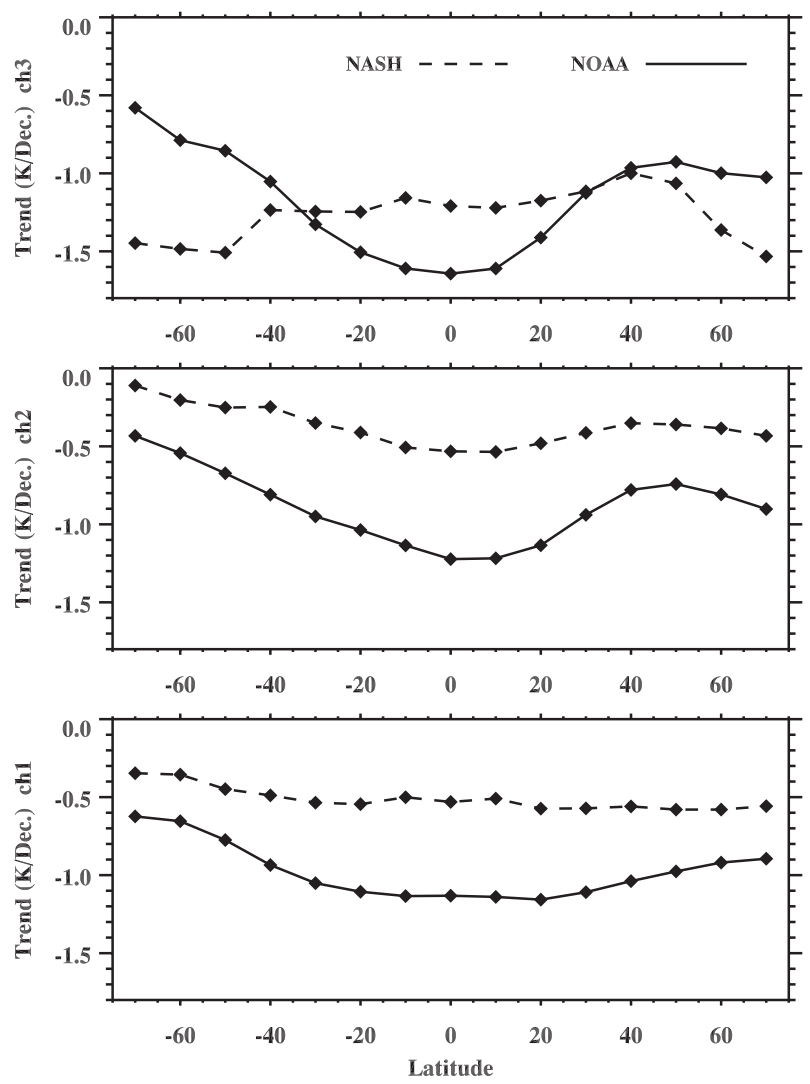

FIG. 19. Latitudinal profiles of mean temperature trends over 1979-2005 derived from Nash (dashed) and NOAA (solid) datasets for three SSU channels.

The latitudinal structures of temperature trends in 1979-2005 in three SSU channels from the two datasets are illustrated in Fig. 19. For our datasets, the three channels show similar latitudinal structure, namely, weaker cooling over high latitudes but enhanced cooling in the tropics. For the Nash dataset, channels 1 and 2 show the similar features, though with smaller trends. However, channel 3 in the Nash dataset shows different latitudinal structure from the other two channels, with enhanced cooling at polar latitudes and relative minima near $40^{\circ} \mathrm{N}$ and $40^{\circ} \mathrm{S}$. These inconsistent latitudinal structures in trends among different channels shown from Nash data are hard to explain.

\section{Summary}

In recognizing the importance of SSU in stratospheric temperature assessment and limitations in previously available SSU datasets, efforts have been made in this study to construct a fully documented, publicly accessible, well-merged long-term SSU dataset for climate change studies. Focusing on methodologies, this study described the details of data-processing procedures to generate the SSU stratospheric temperature records. The procedures include 1) removal of instrument $\mathrm{CO}_{2}$ cell gas leakage effect, 2) correction of atmospheric $\mathrm{CO}_{2}$ concentration increasing effect, 3) limb adjustment, 4) removal of diurnal sampling biases due to satellite orbital drift, and 5) statistical merging from different satellites. The first four adjustments convert SSU observations to those of nadirlike that correspond to identical weighting functions and a fixed local observational time. The last adjustment minimized residual intersatellite biases. Furthermore, lack of overlap observations between NOAA-9 and $N O A A-11$ could potentially cause large uncertainties in trend determinations. To resolve this issue, a doubledifferencing method was applied to successfully merge the two satellites together. Corresponding to channels 1 , 2 , and 3, the reprocessed SSU datasets are composed by well-merged pentad and monthly TMS, TUS, and TTS products with grid resolution $2.5^{\circ}$ latitude by $2.5^{\circ}$ longitude that cover the entire SSU period from 1978 to 2006.

Based on this new SSU dataset, long-term trends of the stratospheric temperature were investigated. From 1979 to 2006 the global mean trends for TMS, TUS, and TTS, are, respectively, $-1.236 \pm 0.131,-0.926 \pm 0.139$, and $-1.006 \pm 0.194 \mathrm{~K} \mathrm{decade}^{-1}$. Spatial trend pattern analyses indicated this cooling trend occurred globally, with enhanced cooling occurring over the tropical stratosphere. The trends of our new SSU dataset have been compared to the previous Nash SSU analysis. It is found that the global mean trends are close to each other for the channel-3 TTS product. However, global trend differences in channel-1 TMS and channel-2 TUS products are as large as $0.5 \mathrm{~K}$ decade $^{-1}$ between the two datasets, with the new SSU data having a greater cooling trend. With respect to the latitudinal structures of temperature trends, the three channels show similar latitudinal structures in NOAA dataset, that is, weaker cooling over high latitudes but enhanced cooling in the tropics. On the other hand, however, inconsistent latitudinal structure of temperature trends between channel 3 and the other two channels is disclosed in Nash dataset.

As a final note, the above constructed SSU data is released on the National Environmental Satellite, Data, and Information Service/Center for Satellite Applications and Research (STAR) web site as version 1.0 SSU dataset (available at http://www.star.nesdis.noaa.gov/smcd/emb/ mscat $/ \mathrm{mscatmain.htm).} \mathrm{Validation} \mathrm{work} \mathrm{is} \mathrm{being} \mathrm{carried}$ out using the GPS radio occultation observations and ground-based lidar measurements. The comparison results will be presented elsewhere in future studies.

Acknowledgments. The work is supported by NOAA Grant NESDISNESDISPO20092001589 (SDS0915). The authors thank the CRTM team including Yong Han, 
Quanhua Liu, Yong Chen, and Fuzhong Weng from NOAA/NESDIS/STAR for their help in the SSU CRTM modeling simulations. Special thanks go to Paul Poli from ECMWF and Chi-Fan Shih from NCAR for proving part of SSU data. Craig Long and Roger Lin from NOAA/ NWS/NCEP/CPC and William Randel from NCAR provided the Nash SSU dataset. The authors wish to thank Craig Long and two anonymous reviewers for their critical review and judicious comments. The views, opinions, and findings contained in this report are those of the authors and should not be construed as an official NOAA or U.S. government position, policy, or decision.

\section{REFERENCES}

Anderson, B. E., and Coauthors, 1996: Airborne observations of spatial and temporal variability of tropospheric carbon dioxide. J. Geophys. Res., 101 (D1), 1985-1997.

Boering, K. A., S. C. Wofsy, B. C. Daube, H. R. Schneider, M. Loewenstein, J. R. Podolske, and T. J. Conway, 1996 Stratospheric mean ages and transport rates from observations of carbon dioxide and nitrous oxide. Science, 274, 1340-1343.

Brindley, H. E., A. J. Geer, and J. E. Harries, 1999: Climate variability and trends in SSU radiances: A comparison of model predictions and satellite observations in the middle stratosphere. J. Climate, 12, 3197-3219.

Brownscombe, J. L., J. Nash, G. Vaughan, and C. F. Rogers, 1985: Solar tides in the middle atmosphere. I: Description of satellite observations and comparison with theoretical calculations at equinox. Quart. J. Roy. Meteor. Soc., 111, 677-689.

Chahine, M. T., and Coauthors, 2008: Satellite remote sounding of mid-tropospheric $\mathrm{CO}_{2}$. Geophys. Res. Lett., 35, L17807, doi:10.1029/2008GL035022.

Chen, Y., Y. Han, Q. Liu, P. V. Delst, and F. Weng, 2011: Community radiative transfer model for Stratospheric Sounding Unit. J. Atmos. Oceanic Technol., 28, 767-778.

Dackson, D. L., and B. J. Soden, 2007: Detection and correction of diurnal sampling bias in HIRS/2 brightness temperatures. J. Atmos. Oceanic Technol., 24, 1425-1438.

Fu, Q., S. Solomon, and P. Lin, 2010: On the seasonal dependence of tropical lower-stratospheric temperature trends. Atmos. Chem. Phys., 10, 2643-2653.

Garcia, R. R., and W. J. Randel, 2008: Acceleration of the BrewerDobson circulation due to increases in greenhouse gases. J. Atmos. Sci., 65, 2731-2739.

Gray, L. J., S. T. Rumbold, and K. P. Shine, 2009: Stratospheric temperature and radiative forcing response to 11-year solar cycle changes in irradiance and ozone. J. Atmos. Sci., 66, 2402-2417.

Han, Y., P. van Delst, Q. Liu, F. Weng, B. Yan, R. Treadon, and J. Derber, 2006: JCSDA Community Radiative Transfer Model (CRTM) - version 1. NOAA Tech. Rep. NESDIS 122, 33 pp.

Kidwell, K. B., cited 1998: NOAA Polar Orbiter data user's guide. [Available online at http://www.ncdc.noaa.gov/oa/pod-guide/ncdc/ docs/podug/index.htm.]

Kobayashi, S., M. Matricardi, D. Dee, and S. Uppala, 2009: Toward a consistent reanalysis of the upper stratosphere based on radiance measurements from SSU and AMSU-A. Quart. J. Roy. Meteor. Soc., 135, 2086-2099.

Lanzante, J. R., S. A. Klein, and D. J. Seidel, 2003: Temporal homogenization of monthly radiosonde temperature data. Part II
Trends, sensitivities, and MSU comparison. J. Climate, 16, 241-262.

Lin, P., Q. Fu, S. Solomon, and J. M. Wallace, 2009: Temperature trend patterns in Southern Hemisphere high latitudes: Novel indicators of stratospheric change. J. Climate, 22, 6325-6341.

Lindzen, R. S., and S. Chapman, 1969: Atmospheric tides. Space Sci. Rev., 10, 3-188.

Liu, Q., and F. Weng, 2009: Recent stratospheric temperature observed from satellite measurements. SOLA, 5, 53-56, doi:10.2151/sola.2009-014.

Long, C., S. Zhou, S.-K. Yang, and A. Butler, cited 2009: Preliminary evaluation of the upper atmosphere in the CFS Reanalysis. [Available online at http://met.nps.edu/climate_ CDPW09/documents/POSTERS/P1.20_Long 34th_CDPW Oct09.pdf.]

Masarie, K. A., and P. P. Tans, 1995: Extension and integration of atmospheric carbon dioxide data into a globally consistent measurement record. J. Geophys. Res., 100, 11 593-11 610.

Mears, C. A., M. C. Schabel, and F. J. Wentz, 2003: A reanalysis of the MSU channel-2 tropospheric temperature record. $\mathrm{J}$. Climate, 16, 3650-3664.

Miller, D. E., J. L. Brownscombe, G. P. Carruthers, D. R. Pick, and K. H. Stewart, 1980: Operational temperature sounding of the stratosphere. Philos. Trans. Roy. Soc. London, 296, 65-71.

Nash, J., 1988: Extension of explicit radiance observations by the Stratospheric Sounding Unit into the lower stratosphere and lower mesosphere. Quart. J. Roy. Meteor. Soc., 114, 1153-1171. , and J. L. Brownscombe, 1983: Validation of the Stratospheric Sounding Unit. Adv. Space Res., 2, 59-62.

and G. F. Forrester, 1986: Long-term monitoring of stratospheric temperature trends using radiance measurements obtained by the TIROS-N series of NOAA spacecraft. $A d v$. Space Res., 6, 37-44.

Ramaswamy, V., and Coauthors, 2001: Stratospheric temperature trends: Observations and model simulations. Rev. Geophys., 39, 71-122.

Randel, W. J., and Coauthors, 2009: An update of observed stratospheric temperature trends. J. Geophys. Res., 114, D02107, doi:10.1029/2008JD010421.

Rienecker, M. M., and Coauthors, 2011: MERRA-NASA's Modern-Era Retrospective Analysis for Research and Applications. J. Climate, 24, 3624-3648.

Santer, B. D., T. M. L. Wigley, J. S. Boyle, D. J. Gaffen, J. J. Hnilo, D. Nychka, D. E. Parker, and K. E. Taylor, 2000: Statistical significance of trends and trend differences in layer-average atmospheric temperature time series. J. Geophys. Res., 105, 7337-7356.

Seidel, D. J., M. Free, and J. Wang, 2005: Diurnal cycle of upper air temperature estimated from radiosondes. J. Geophys. Res., 110, D09102, doi:10.1029/2004JD005526.

, N. P. Gillett, J. R. Lanzante, K. P. Shine, and P. W. Thorne, 2011: Stratospheric temperature trends: Our evolving understanding. Wiley Interdiscip. Rev.: Climate Change, 2, 592616, doi:10.1002/wcc. 125.

Shine, K. P., and Coauthors, 2003: A comparison of model-simulated trends in stratospheric temperatures. Quart. J. Roy. Meteor. Soc., 129, 1565-1588.

— , J. J. Barnett, and W. J. Randel, 2008: Temperature trends derived from stratospheric sounding unit radiances: The effect of increasing $\mathrm{CO}_{2}$ on the weighting function, 441. Geophys. Res. Lett., 35, L02710, doi:10.1029/2007GL032218.

Strow, L., S. Hannon, D. Tobin, and H. Revercomb, 2008: Intercalibration of the AIRS and IASI operational infrared sensors. 
Proc. 17th Annual Conf. on Characterization and Radiometric Calibration for Remote Sensing (CALCON), Logan, UT, Utah State University Research Foundation, CD-ROM.

Thompson, D. W. J., and S. Solomon, 2005: Recent stratospheric climate trends as evidenced in radiosonde data: Global structure and tropospheric linkages. J. Climate, 18, 4785-4795.

Thoning, K. W., P. P. Tans, and W. D. Komhyr, 1989: Atmospheric carbon dioxide at Mauna Loa Observatory 2. Analysis of the NOAA GMCC data, 1974-1985. J. Geophys. Res., 94, 8549-8565.

Wang, L., X. Wu, M. Goldberg, C. Cao, Y. Li, and S.-H. Sohn, 2010: Comparison of AIRS and IASI radiances using GOES imagers as transfer radiometers toward climate data records. J. Appl. Meteor. Climatol., 49, 478-492.

World Meteorological Organization, 1988: Report of the International Ozone Trends Panel 1988. Global Ozone Research Monitoring Project Rep. 19, 829 pp.
— 2007: Scientific assessment of ozone depletion: 2006. Global Ozone Research Monitoring Project Rep. 50, 572 pp.

Young, P. J., S. Solomon, D. W. J. Thompson, K. H. Rosenlof, and J.-F. Lamarque, 2011: The seasonal cycle and interannual variability in stratospheric temperatures and links to the Brewer-Dobson circulation: An analysis of MSU and SSU data. J. Climate, 24, 6243-6258.

,,,--- S. C. Sherwood, K. H. Rosenlof, Q. Fu, and J.-F. Lamarque, 2012: Changes in stratospheric temperatures and their implications for changes in the Brewer-Dobson circulation, 1979-2005. J. Climate, 25, 1759-1772.

Zou, C.-Z., and W. Wang, 2010: Stability of the MSU-derived atmospheric temperature trend. J. Atmos. Oceanic Technol., 27, 1960-1971.

—, M. Gao, and M. Goldberg, 2009: Error structure and atmospheric temperature trends in observations of the Microwave Sounding Unit. J. Climate, 22, 1661-1681. 